\title{
Preparation of Tetraethylenepentamine Modified Magnetic Graphene Oxide for Adsorption of Dyes from Aqueous Solution
}

\author{
Xiaosheng Tang, ${ }^{a}$ Ping Tang ${ }^{b, c}$ and Liangliang Liu ${ }^{*, b}$ \\ ${ }^{a}$ Hubei Key Laboratory of Edible Wild Plants Conservation and Utilization \& National \\ Demonstration Center for Experimental Biology Education \& College of Life Sciences, \\ Hubei Key Laboratory of Pollutant Analysis \& Reuse Technology, Hubei Normal University, \\ 435002 Huangshi, Hubei, China
}

${ }^{b}$ Institute of Bast Fiber Crops, Chinese Academy of Agricultural Sciences, 410205 Changsha, China

'School of Environmental Science and Engineering, Hubei Polytechnic University, Hubei Key Laboratory of Mine Environmental Pollution Control and Remediation, 435003 Huangshi, Hubei, China

In this study, tetraethylenepentamine modified magnetic graphene oxide nanomaterial (TMGO) was prepared and characterized by transmission electron microscopy (TEM), Fourier transform infrared spectroscopy (FTIR), Raman spectroscopy, thermogravimetric analysis (TGA), $\mathrm{X}$-ray photoelectron spectroscopy (XPS) and vibration sample magnetometer (VSM). All the characterizations proved that the modification and preparation of TMGO were successful. The TMGO nanomaterial was used in the adsorption of Acid Red 18 (AR) in aqueous solution. The parameters like $\mathrm{pH}$ of solution, adsorption kinetics and isotherms were all investigated. The results indicated that the TMGO nanomaterial had satisfied adsorption ability and the maximum adsorption capacity was $524.2 \mathrm{mg} \mathrm{g}^{-1}$ at $45{ }^{\circ} \mathrm{C}$ and $\mathrm{pH}$ 6. The adsorption capacity remained at $91.8 \%$ of the initial value after five cycles. The adsorption process with AR was found through fitting the pseudo-second-order kinetics equations and the Freundlich adsorption model. The experimental results demonstrated that the TMGO nanomaterial could be rapidly extracted from the medium and had a good adsorption ability to remove dyes in wastewater.

Keywords: adsorption, dye, graphene oxide, magnetic nanoparticles, tetraethylenepentamine

\section{Introduction}

Increasing interests were focused on the environmental health, especially the removal of toxic organic or inorganic pollutants from water because of the water pollution during the development of modern industry. ${ }^{1}$ Among the various toxic pollutants, dye was one of the most serious problems because of the visible color, complex component and low biodegradability. ${ }^{2}$ Dye was widely used in direct textiles, printing and dyeing. It showed many damages to plants, animals and human beings. ${ }^{3}$ Therefore, wastewater containing dyes should be treated adequately before being discharged. ${ }^{4}$ The development of materials for removal of dyes exhibited considerable importance.

Recently, many kinds of materials and nanomaterials such as silica nanoparticles, carbon nanotube, gold

*e-mail: liuliangliang@caas.cn nanoparticles and metal oxide nanoparticles were utilized as adsorbents for removal of toxic compounds..$^{5-8}$ Graphene oxide (GO) attracted significant interests due to its high mechanical strength and facile functionalization ability. ${ }^{9}$ It could be a good material for adsorption owing to the large specific surface area, abundant oxygen containing groups and high water solubility. ${ }^{10-12}$ Magnetic nanoparticles (MN) were also good in separation of toxic dyes by simply using an ordinary magnet. ${ }^{13,14}$ After the combination of $\mathrm{MN}$ and GO, magnetic GO (MGO) and related complex nanomaterials were prepared and used in pollution control and sensors were benefited from the advantages of both $\mathrm{MN}$ and GO. ${ }^{15-18}$ During the various kinds of applications, many advantages of MGO were demonstrated including high adsorption capacity, easy recycling and improved stability.

In this study, tetraethylenepentamine was used in the modification of $\mathrm{Fe}_{3} \mathrm{O}_{4}$ magnetic nanoparticle (TMN) 
to increase amino groups and ultimately increase the interaction between adsorbent and dye molecule. The TMN was then bound on the surface of GO (TMGO) and the final nanomaterial was applied in the adsorption of Acid Red 18 (AR). The prepared materials were characterized by transmission electron microscopy (TEM), Fourier transform infrared spectroscopy (FTIR), Raman spectroscopy, thermogravimetric analysis (TGA), X-ray photoelectron spectroscopy (XPS) and vibration sample magnetometer (VSM). In order to obtain the optimum reaction condition, effect of $\mathrm{pH}$ on the adsorption of AR and the reusability of TMGO were investigated. Kinetics and isotherms parameters of the adsorption were also determined. The experimental results showed that TMGO had a satisfied adsorption capacity and could be regenerated.

\section{Experimental}

\section{Chemicals and materials}

Graphite flake (100 mesh) was purchased from Nanjing XFNANO Materials Tech Co., Ltd. (Nanjing, China). 1-Ethyl-3-(3-dimethylaminopropyl) carbodiimide (EDC), N-hydroxy sulfosuccinimide (NHS) and 3-aminopropyltriethoxysilane and glutaraldehyde were acquired from Sigma-Aldrich Chemicals (St. Louis, MO, USA). Tetraethylenepentamine and Acid Red 18 (AR) were obtained commercially from Aladdin (Shanghai, China). Ferric chloride hexahydrate $\left(\mathrm{FeCl}_{3} \cdot 6 \mathrm{H}_{2} \mathrm{O}, 98 \%\right)$, polyethyleneglycol (PEG 6000) were purchased from Sinopharm Chemical Reagent (Shanghai, China). Ultrapure water (18.2 $\mathrm{M} \Omega \mathrm{cm}$ resistivity) was obtained from an ELGA water purification system (ELGA Berkefeld, Veolia, Germany). All of other chemicals were analytical grade and purchased from Sinopharm Chemical Reagent Co., Ltd. (Shanghai, China).

\section{Synthesis of TMN}

MN was synthesized by solvothermal method. $1.350 \mathrm{~g}$ of $\mathrm{FeCl}_{3} \cdot 6 \mathrm{H}_{2} \mathrm{O}, 1.000 \mathrm{~g}$ of PEG 6000 and $3.600 \mathrm{~g}$ of anhydrous sodium acetate were mixed in $40 \mathrm{~mL}$ of ethyleneglycol with 30 min stirring. The solution was then transferred into a stainless steel autoclave and maintained at $180{ }^{\circ} \mathrm{C}$ for $8 \mathrm{~h}$. Finally, the $\mathrm{Fe}_{3} \mathrm{O}_{4} \mathrm{MN}$ was washed with ethanol for three times through magnetic separation and dried in vacuum at $40{ }^{\circ} \mathrm{C}$.

$0.100 \mathrm{~g}$ of $\mathrm{MN}$ was dispersed in $200 \mathrm{~mL}$ of ethanol with $30 \mathrm{~min}$ mechanical agitation. $2 \mathrm{~mL}$ of 3-aminopropyltriethoxysilane was then dropwise added and the solution was stirred for $6 \mathrm{~h}$ at room temperature. The obtained amino-MN was washed with ethanol for three times and transferred in $50 \mathrm{~mL}$ of water containing $5 \%$ glutaraldehyde. After shaken for $30 \mathrm{~min}, 2 \mathrm{~mL}$ of tetraethylenepentamine $\left(1.0 \mathrm{mg} \mathrm{mL} \mathrm{mL}^{-1}\right)$ was added to the mixture. After further $30 \mathrm{~min}$ shaken, redundant tetraethylenepentamine was removed. The final TMN was washed for three times with ethanol and dried in vacuum at $40{ }^{\circ} \mathrm{C}$.

\section{Synthesis of GO}

GO was prepared according to the improved hummer method reported by Marcano et al. ${ }^{19}$ Briefly, $13 \mathrm{~mL}$ of $\mathrm{H}_{3} \mathrm{PO}_{4}, 120 \mathrm{~mL}$ of concentrated $\mathrm{H}_{2} \mathrm{SO}_{4}, 6.000 \mathrm{~g}$ of $\mathrm{KMnO}_{4}$ and $1.000 \mathrm{~g}$ of graphite flakes were mixed and kept at $50{ }^{\circ} \mathrm{C}$ for $12 \mathrm{~h}$ with magnetic stirring. Then the mixture was poured into $130 \mathrm{~mL}$ of ice containing $3 \mathrm{~mL}$ of $30 \%$ $\mathrm{H}_{2} \mathrm{O}_{2}$. The mixture was centrifuged for $30 \mathrm{~min}$ and the supernatant was decanted. Then the remaining solid was washed with $30 \% \mathrm{HCl}$ and water for five times, respectively. For each wash, the mixture was centrifuged for $30 \mathrm{~min}$ and the supernatant was decanted. The finally obtained solid material was dried in vacuum at $40{ }^{\circ} \mathrm{C}$.

\section{Synthesis and characterizations of TMGO}

$0.100 \mathrm{~g}$ of $\mathrm{GO}$ was dispersed in $50 \mathrm{~mL}$ of water. EDC $(0.1 \mathrm{M})$ and NHS $(0.1 \mathrm{M})$ were then added to the GO dispersion and shaken for $1 \mathrm{~h} .0 .150 \mathrm{~g}$ of TMN was added in the GO dispersion and shaken for $30 \mathrm{~min}$. The obtained TMGO was finally collected by magnetic separation and dried in vacuum at $40{ }^{\circ} \mathrm{C}$.

In order to characterize the obtained TMGO, TEM images of MN and TMGO were recorded on a JEOL200CX electron microscope (Jeol, Tokyo, Japan). Magnetic properties of MN, TMN and TMGO were performed on a Lakeshore 7407 vibrating sample magnetometer (VSM, Westerville, Ohio, USA) at room temperature. FTIR spectra were obtained using a Nicolet avatar 360 FTIR spectrophotometer (Thermo Fisher Nicolet, Orlando, USA) and samples were dried at $40^{\circ} \mathrm{C}$ in vacuum for at least $12 \mathrm{~h}$ prior to fabrication of the $\mathrm{KBr}$ pellet. The Raman spectrum was measured by using a Raman Microscope (LabRAM HR Evolution, Horiba, Kyoto, Japan). TGA was performed in nitrogen atmosphere from 50 to $800{ }^{\circ} \mathrm{C}$ with a heating rate of $10{ }^{\circ} \mathrm{C} \mathrm{min}^{-1}$ using a simultaneous thermal analyzer (Netzsch STA 449F3, Ahlden, Germany). XPS was used to analyze the surface elemental composition by K-Alpha XPS spectrometer (Thermo Fisher Scientific Inc., Waltham, MA, USA). 


\section{Adsorption of AR with TMGO}

$10 \mathrm{mg}$ of TMGO was added into $40 \mathrm{~mL}$ of AR solution with certain concentrations $\left(50,75,100,125,150 \mathrm{mg} \mathrm{L}^{-1}\right)$ and the mixture was shaken for $120 \mathrm{~min}$ at 25,35 and $45^{\circ} \mathrm{C}$. The final concentration of AR was determined by UV-Vis spectrophotometer (Shimadzu, Kyoto, Japan) at $490 \mathrm{~nm}$. To study the effects of initial $\mathrm{pH}$ on the adsorption of AR, initial $\mathrm{pH}$ values of the solution were adjusted to 4, 5, 6, 7, 8 and 9 by adding hydrochloric acid or sodium hydroxide at $45^{\circ} \mathrm{C}$. All the assays were operated with three replicates.

\section{Adsorption kinetics and isotherm}

$10 \mathrm{mg}$ of TMGO was added into $40 \mathrm{~mL}$ of $\mathrm{AR}$ solution (150 $\mathrm{mg} \mathrm{L}^{-1}$ ). The mixture was shaken at $25{ }^{\circ} \mathrm{C}$ and the concentration of AR was determined at certain intervals. Pseudo-first-order and pseudo-second-order kinetic models were used to evaluate the sorption kinetics. The pseudo-first-order kinetic model could be expressed by the following equation:

$\ln \left(\mathrm{q}_{\mathrm{e}}-\mathrm{q}_{\mathrm{t}}\right)=\ln \mathrm{q}_{\mathrm{e}}-\mathrm{k}_{1} \mathrm{t}$

where $\mathrm{q}_{\mathrm{e}}\left(\mathrm{mg} \mathrm{g}^{-1}\right)$ is the equilibrium adsorption capacity, $\mathrm{q}_{\mathrm{t}}$ $\left(\mathrm{mg} \mathrm{g}^{-1}\right)$ is the amount of adsorbate at time $\mathrm{t}, \mathrm{k}_{1}\left(\mathrm{~g} \mathrm{mg}^{-1} \mathrm{~min}^{-1}\right)$ is the rate constant of adsorption. And the pseudo-secondorder kinetic model could be expressed by the following equation:

$\frac{\mathrm{t}}{\mathrm{q}_{\mathrm{t}}}=\frac{1}{\mathrm{k}_{\mathrm{ad}} \mathrm{q}_{\mathrm{e}}^{2}}+\frac{1}{\mathrm{q}_{\mathrm{e}}} \mathrm{t}$

where $\mathrm{k}_{\mathrm{ad}}\left(\mathrm{g} \mathrm{mg}^{-1} \mathrm{~min}^{-1}\right)$ is the rate constant of adsorption, $\mathrm{q}_{\mathrm{e}}$ $\left(\mathrm{mg} \mathrm{g}^{-1}\right)$ is the equilibrium adsorption capacity, $\mathrm{q}_{\mathrm{t}}\left(\mathrm{mg} \mathrm{g}^{-1}\right)$ is the amount of adsorbate at time..$^{20,21}$

For the adsorption isotherm, $10 \mathrm{mg}$ of TMGO was added into $40 \mathrm{~mL}$ of $\mathrm{AR}$ solution at the concentration range of 50-150 $\mathrm{mg} \mathrm{L}^{-1}$. The mixtures were shaken at 25, 35 and $45^{\circ} \mathrm{C}$ for $120 \mathrm{~min}$ and the concentration of AR was determined to study the adsorption isotherm. Langmuir and Freundlich equations were used to evaluate adsorption isotherm. The Langmuir isotherm could be expressed as follows:

$\frac{\mathrm{C}_{\mathrm{e}}}{\mathrm{q}_{\mathrm{e}}}=\frac{1}{\mathrm{bq}_{\mathrm{m}}}+\frac{\mathrm{C}_{\mathrm{e}}}{\mathrm{q}_{\mathrm{m}}}$

where $\mathrm{C}_{\mathrm{e}}\left(\mathrm{mg} \mathrm{L}^{-1}\right)$ is the equilibrium concentration of $\mathrm{AR}$ solution, $\mathrm{q}_{\mathrm{m}}$ and $\mathrm{b}$ are the maximum adsorption capacity $\left(\mathrm{mg} \mathrm{g}^{-1}\right)$ and the equilibrium adsorption constant $\left(\mathrm{L} \mathrm{mg}^{-1}\right)$.
On the contrary, the Freundlich isotherm could be given as the following equation:

$\log \mathrm{q}_{\mathrm{e}}=\log \mathrm{k}+\frac{1}{\mathrm{n}} \log \mathrm{C}_{\mathrm{e}}$

where $\mathrm{C}_{\mathrm{e}}\left(\mathrm{mg} \mathrm{L}^{-1}\right)$ is the equilibrium concentration of AR solution, $\mathrm{q}_{\mathrm{e}}\left(\mathrm{mg} \mathrm{g}^{-1}\right)$ is the adsorption capacity at equilibrium, $\mathrm{k}\left(\mathrm{L} \mathrm{mg}^{-1}\right)$ and $\mathrm{n}$ are the Freundlich constants. ${ }^{22}$

\section{Reusability of TMGO}

$10 \mathrm{mg}$ of TMGO was added into $40 \mathrm{~mL}$ of AR solution (150 $\mathrm{mg} \mathrm{L}^{-1}$ ) and the mixture was shaken for $120 \mathrm{~min}$ at $45^{\circ} \mathrm{C}$. The final concentration of AR was determined and the TMGO was washed with ethanol and water for three times ( $5 \mathrm{~mL}$ of solution in each time). Then the TMGO was added into another AR solution to start a new cycle. The results were shown as the relative adsorption capacity. All the assays were operated with three replicates.

\section{Results and Discussion}

\section{Characterization of TMGO}

TEM images of MN and TMGO were presented in Figure 1. As shown in Figure 1a, the MN showed round shape and the range of size distribution of MN was mainly from 420 to $480 \mathrm{~nm}$. The average diameter of $\mathrm{MN}$ was about $450 \mathrm{~nm}$. Some MN with the diameter smaller than average value also existed. However, the synthesis of material and adsorption would not be affected by the small size of MN. After the combination (Figure 1b), it could be seen that TMN bound with GO and characteristics of GO like sheetlike structure and wrinkled edge could be also observed. ${ }^{23}$
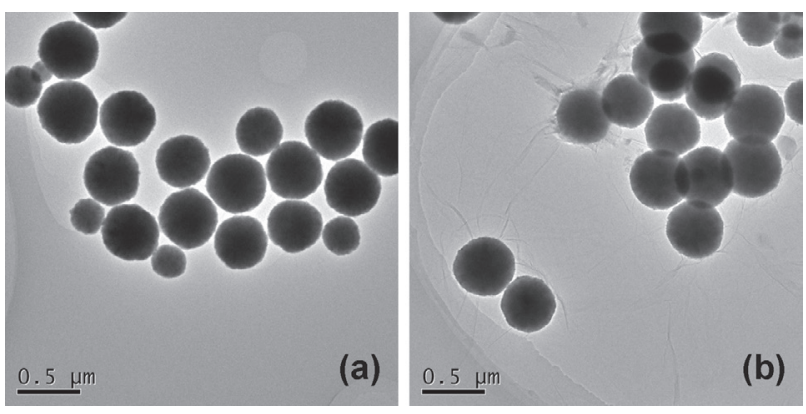

Figure 1. TEM images of (a) MN and (b) TMGO.

The TMGO was obtained from the condensation reaction between the amino group of TMN and carboxylic group of GO using EDC and NHS as cross-linking agents. The formed carboxamide bonding between GO and TMN 
was studied through FTIR spectroscopy. Figure 2 showed the FTIR spectra of MN, TMN, GO and TMGO. The FTIR spectrum of MN showed the characteristic peak at $574 \mathrm{~cm}^{-1}$ corresponding to the $\mathrm{Fe}-\mathrm{O}$ stretching vibration. Two bands observed in the spectrum of TMN at 1631 and $3415 \mathrm{~cm}^{-1}$ could be assigned to the $\mathrm{N}-\mathrm{H}$ bending and stretching vibrations of free amino groups on TMN surface. ${ }^{24}$ For the spectrum of GO, the peaks at 3428 and $1629 \mathrm{~cm}^{-1}$ were assigned to the $\mathrm{O}-\mathrm{H}$ stretching vibration and the $\mathrm{C}=\mathrm{O}$ stretching vibration of the carboxyl group, respectively. ${ }^{25,26}$ In the spectrum of TMGO, all feature peaks of GO and TMN could be observed, and all peaks confirmed that the preparation of TMGO was successful.

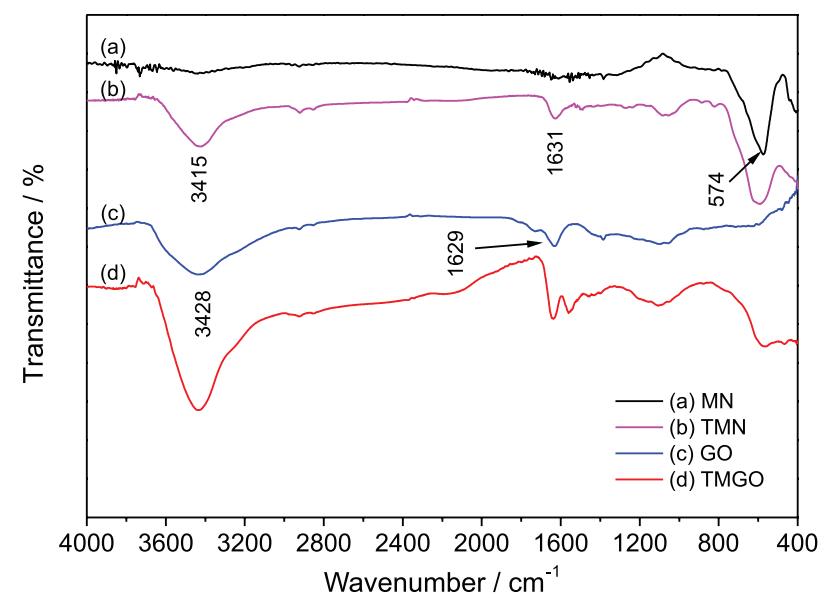

Figure 2. FTIR spectra of (a) MN, (b) TMN, (c) GO and (d) TMGO.

Raman spectroscopy was used to characterize carbon materials such as GO. Figure 3 showed the Raman spectrum of TMGO. The TMGO exhibited D band usually at $1340 \mathrm{~cm}^{-1}$, representing the disordered $\mathrm{sp}^{3}$ carbon structure, and a $\mathrm{G}$ band usually at $1575 \mathrm{~cm}^{-1}$, representing the $\mathrm{sp}^{2}$ ordered crystalline graphite-like structures. ${ }^{27}$ The intensity ratio of the $D$ to $G$ peak $\left(I_{D} / I_{G}\right)$ for the Raman spectroscopy of TMGO was 1.04 . The high ratio reflected the increased disorder of the $\mathrm{sp}^{2}$ domain within the materials. ${ }^{28}$

TGA was performed to determine the thermal stability of prepared materials. Figure 4 showed the TGA curves of MN, TMN and TMGO. The weight loss below $200{ }^{\circ} \mathrm{C}$ was related to the evaporation of absorbed water molecules. When the temperature reached $800^{\circ} \mathrm{C}$, the total weight loss of MN and TMN were 7.1 and $10.3 \%$, respectively, which indicated the modification of organic groups on MN. While on the TGA curve of TMGO, the most significant mass loss of $\mathrm{GO}$ occurred below $200{ }^{\circ} \mathrm{C}$ due to water produced by the decomposition of labile hydroxyl and carboxyl groups. ${ }^{29}$ Finally, the total weight loss of TMGO reached $43.9 \%$ when the temperature reached $800^{\circ} \mathrm{C}$. It could be concluded that

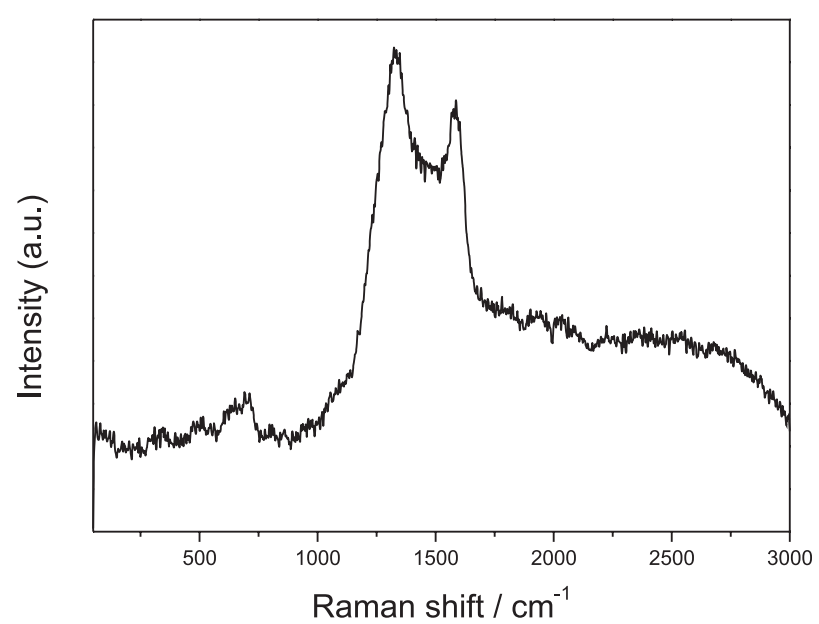

Figure 3. Raman spectra of TMGO.

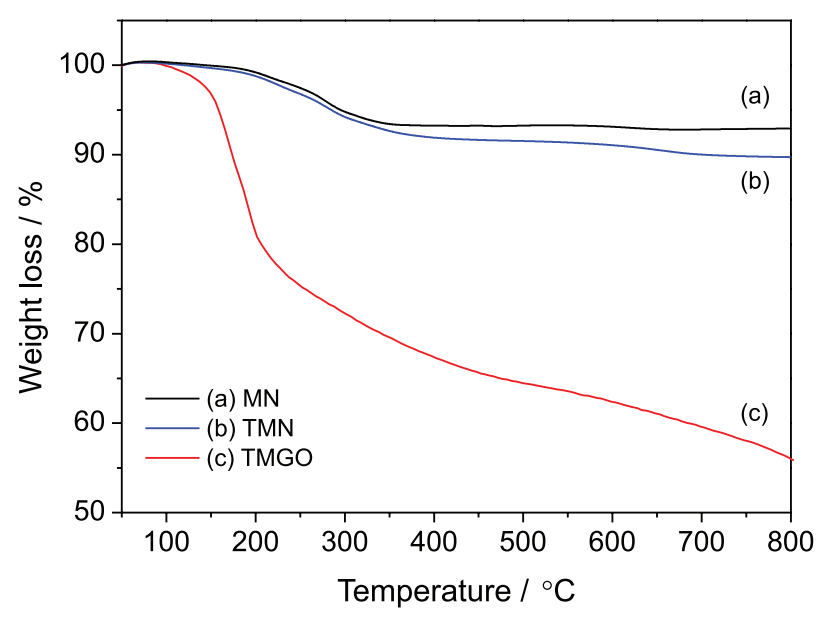

Figure 4. TGA curves of (a) MN, (b) TMN and (c) TMGO.

the modification of MN and the combination of GO and TMN was effective.

The elemental composition and chemical status of TMGO were analyzed by XPS. Figure 5a showed the full survey scan of XPS spectra for TMGO. The sharp peaks in Figure 5a indicated the presence of carbon $(\mathrm{C} 1 \mathrm{~s})$, oxygen $(\mathrm{O} 1 \mathrm{~s})$, nitrogen $(\mathrm{N} 1 \mathrm{~s})$, and iron $(\mathrm{Fe} 2 \mathrm{p})$ elements in TMGO. The XPS C1s, O1s, N1s and Fe2p spectra were summarized in Figures 5b-5e to further investigate the relative contents of core groups in TMGO. In the spectrum of $\mathrm{C} 1 \mathrm{~s}$ of TMGO (Figure 5b), the strong peaks at 284.8 and $286.6 \mathrm{eV}$ indicated the saturated $\mathrm{C}-\mathrm{C}$ bonding in graphene framework and the carbon in hydroxyl and epoxy groups $(\mathrm{C}-\mathrm{O}-\mathrm{C})$ of GO. The peak at $288.0 \mathrm{eV}$ was due to the carbonyl carbon $(\mathrm{C}=\mathrm{O})$ on $\mathrm{GO} .{ }^{30}$ The XPS spectrum of $\mathrm{O} 1 \mathrm{~s}$ of TMGO (Figure $5 \mathrm{c}$ ) indicated the $\mathrm{Fe}-\mathrm{O}$ bond in iron oxide at $529.7 \mathrm{eV}$, the hydroxyl group at $531.1 \mathrm{eV}$ and the $\mathrm{C}-\mathrm{O}$ bond at $532.3 \mathrm{eV}$, all observed on the TMGO surface. The XPS spectrum of N1s of TMGO (Figure 5d) showed 
two peaks at 399.4 and $401.4 \mathrm{eV}$, which were attributed to the $\mathrm{NH}_{2}$ (amine) and $\mathrm{O}=\mathrm{C}-\mathrm{N}$ (amide) bonds in TMGO. ${ }^{31} \mathrm{It}$ indicated the modification of amino groups on the materials was successful. Figure 5e showed the XPS spectrum of Fe2p of TMGO. The peaks at 723.2 and $710.1 \mathrm{eV}$ were attributed to $\mathrm{Fe}_{3} \mathrm{O}_{4}$, while the peaks at $732.0 \mathrm{eV}\left(\mathrm{Fe}_{2} \mathrm{O}_{3}\right)$,
$724.6 \mathrm{eV}\left(\mathrm{Fe} 2 \mathrm{p}_{1 / 2}\right)$ and $711.7 \mathrm{eV}\left(\mathrm{Fe} 2 \mathrm{p}_{3 / 2}\right)$ were assigned to $\mathrm{Fe}_{2} \mathrm{O}_{3}{ }^{32}$ These peaks indicated the existence of $\mathrm{Fe}_{3} \mathrm{O}_{4}$ and $\mathrm{Fe}_{2} \mathrm{O}_{3}$ on TMGO.

The magnetic properties of MN, TMN and TMGO were determined by VSM at room temperature. Figure 6 showed the saturation magnetization curves. The saturation
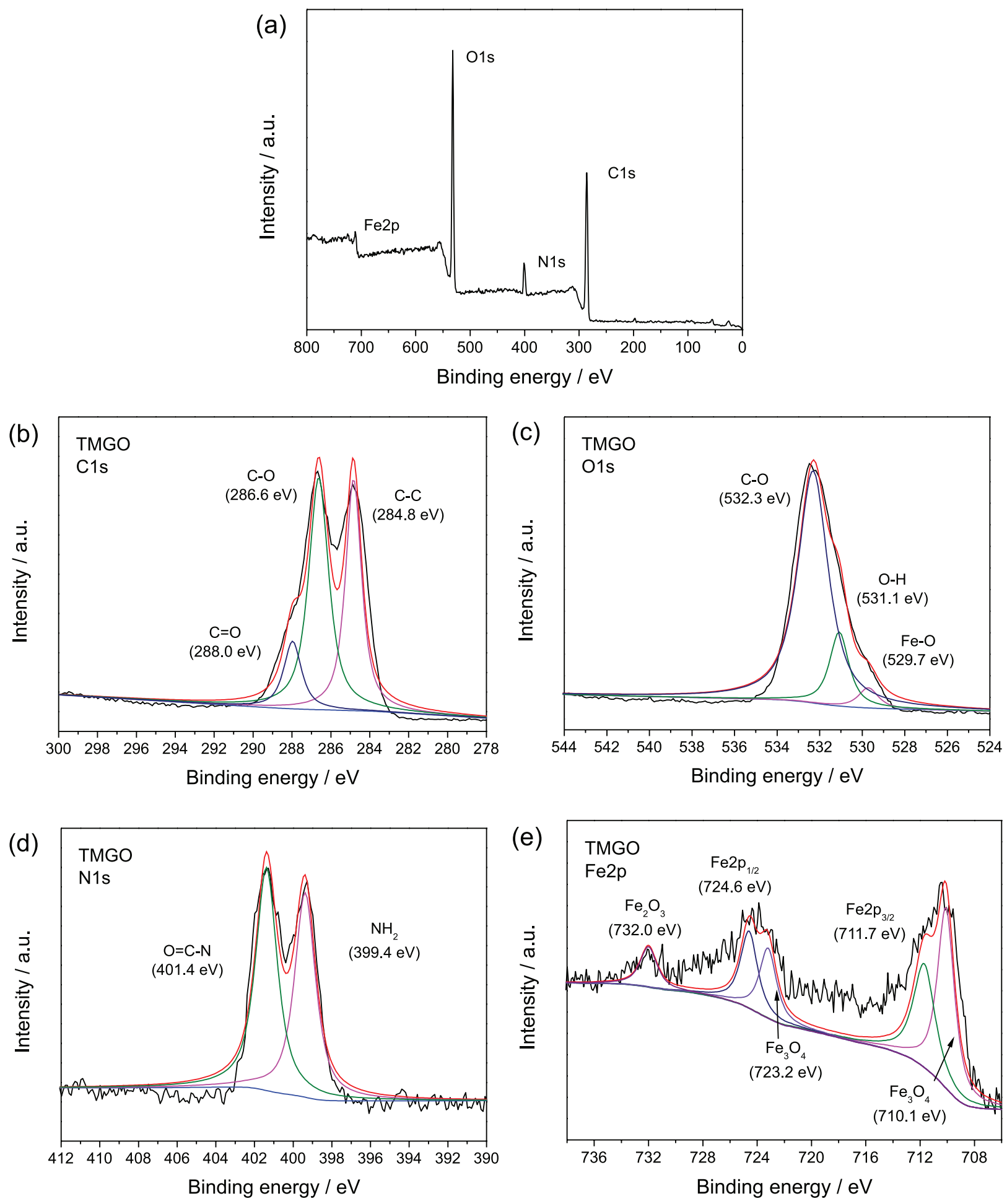

Figure 5. XPS spectra of survey scan of TMGO (a), high-resolution scan of C1s (b), O1s (c), N1s (d) and Fe2p (e) of TMGO. 
magnetization of $\mathrm{MN}$ was $74.9 \mathrm{emu}^{-1}$, whereas the saturation magnetizations of TMN and TMGO were 56.7 and $32.4 \mathrm{emu} \mathrm{g}^{-1}$, respectively, which were lower than that of MN. The decrease of saturation magnetizations after modification and combination could be contributed to the existence of non-magnetic materials. ${ }^{33}$ These features of TMGO made the highly efficient magnetic separation available with ordinary external magnetic field.

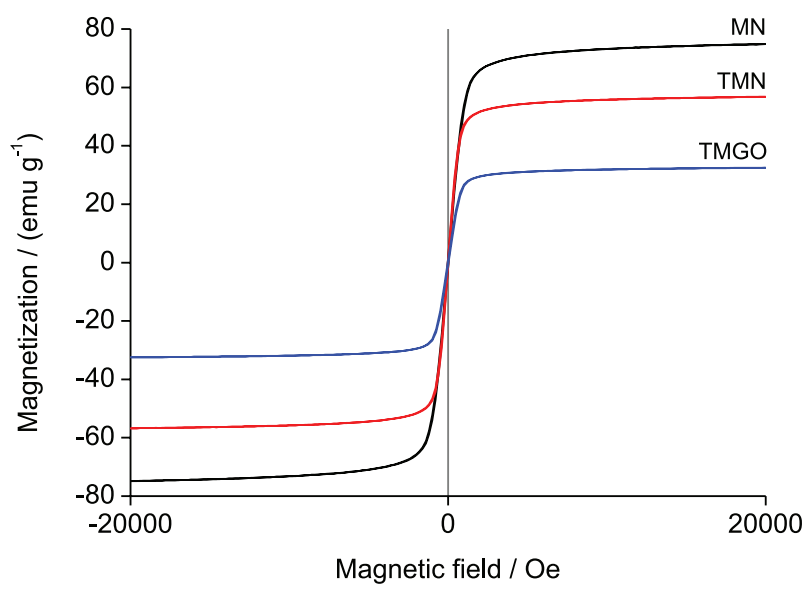

Figure 6. Magnetization curves of MN (black), TMN (blue) and TMGO (red).

\section{Effect of $\mathrm{pH}$}

The $\mathrm{pH}$ of solution would affect the adsorption capacity of adsorbent and showed impact on the electrostatic interaction between dye and adsorbent surface. The effect of $\mathrm{pH}$ on the adsorption capacity of AR was studied in the range of 4 to 9 (Figure 7). As a result, the relative adsorption capacity reached maximum when $\mathrm{pH}$ was 6 . At acidic $\mathrm{pH}$ region, the surface of adsorbent becomes highly positively charged due to increased protonation of the amine group. The amino cations of TMGO could interact with sulfonate anions of anionic dye by electrostatic adsorption. ${ }^{34}$ The optimum $\mathrm{pH}$ value was in accordance with the reported research. ${ }^{35,36}$ Furthermore, the lower adsorption of anionic dye at higher $\mathrm{pH}$ values could be attributed to the electrostatic repulsion between negatively charged adsorbents and anionic AR dye, ${ }^{37}$ and the increasing competition for sites between $\mathrm{OH}^{-}$ions and anionic dye ions. ${ }^{35}$

\section{Adsorption kinetics}

The adsorption kinetics of AR were shown in Figure 8a. In the first $45 \mathrm{~min}$, the adsorption amount of AR apparently increased and then the increase trend slowed down. After $120 \mathrm{~min}$, the adsorption reached equilibrium,

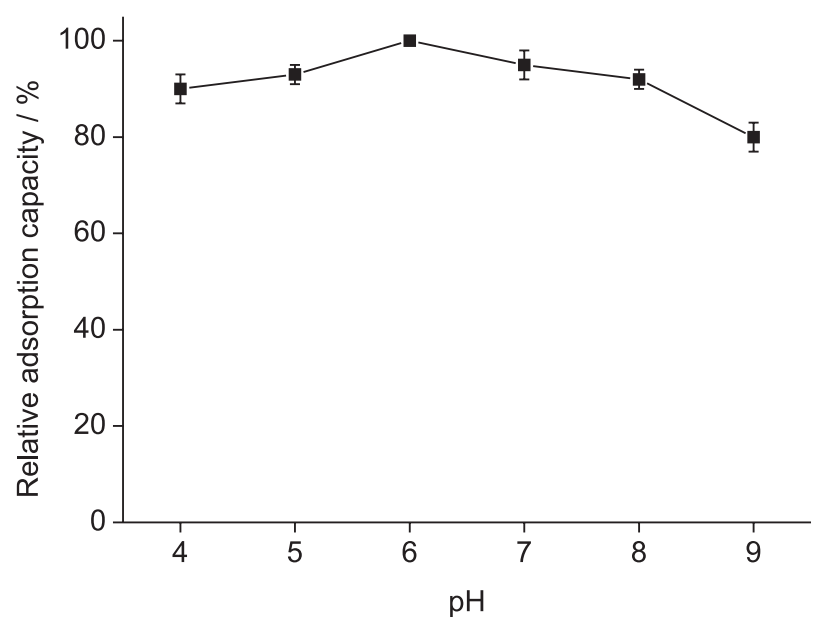

Figure 7. The influence of initial $\mathrm{pH}$ on the adsorption of AR.

thus 120 min was selected as the adsorption time. The adsorption of AR was fitted with the pseudo-first-order and pseudo-second-order kinetic models. The results showed that the adsorption fitted well with pseudo-second-order kinetic equation (Figures $8 \mathrm{~b}$ and $8 \mathrm{c}$ ) and the correlation coefficient of fitting model reached 0.995 , while the correlation coefficient of fitting pseudo-first-order model was 0.982 . It could be suggested that pseudo-second-order model was the optimal candidate in explicating AR adsorption.

\section{Adsorption isotherm}

Adsorption isotherm was important for determining the adsorption behavior of an adsorbent. The isotherm data for the adsorption of AR on TMGO were fitted with the Langmuir and Freundlich models. Figure 9 showed the adsorption isotherm and the parameters of the Langmuir and Freundlich models were listed in Table 1. The adsorption capacity of AR at $45^{\circ} \mathrm{C}$ reached $524.2 \mathrm{mg} \mathrm{g}^{-1}$. As shown in Figure 9 and Table 1, the Freundlich Langmuir model fitted better than the Langmuir model. It demonstrated that the adsorption of AR on TMGO could be considered as a monolayer adsorption process.

\section{Reusability of TMGO}

The reusability of TMGO was shown in Figure 10. The relative adsorption capacity of TMGO decreased gradually during five cycle usage and the relative adsorption capacity of TMGO remained $91.8 \%$ after five cycles. The decrease in adsorption capacity might be caused by the incomplete desorption of dyes from TMGO and the loss of TMGO in repeated operations. ${ }^{38,39}$ The result indicated that TMGO was a cost effective material for the removal of dyes. 

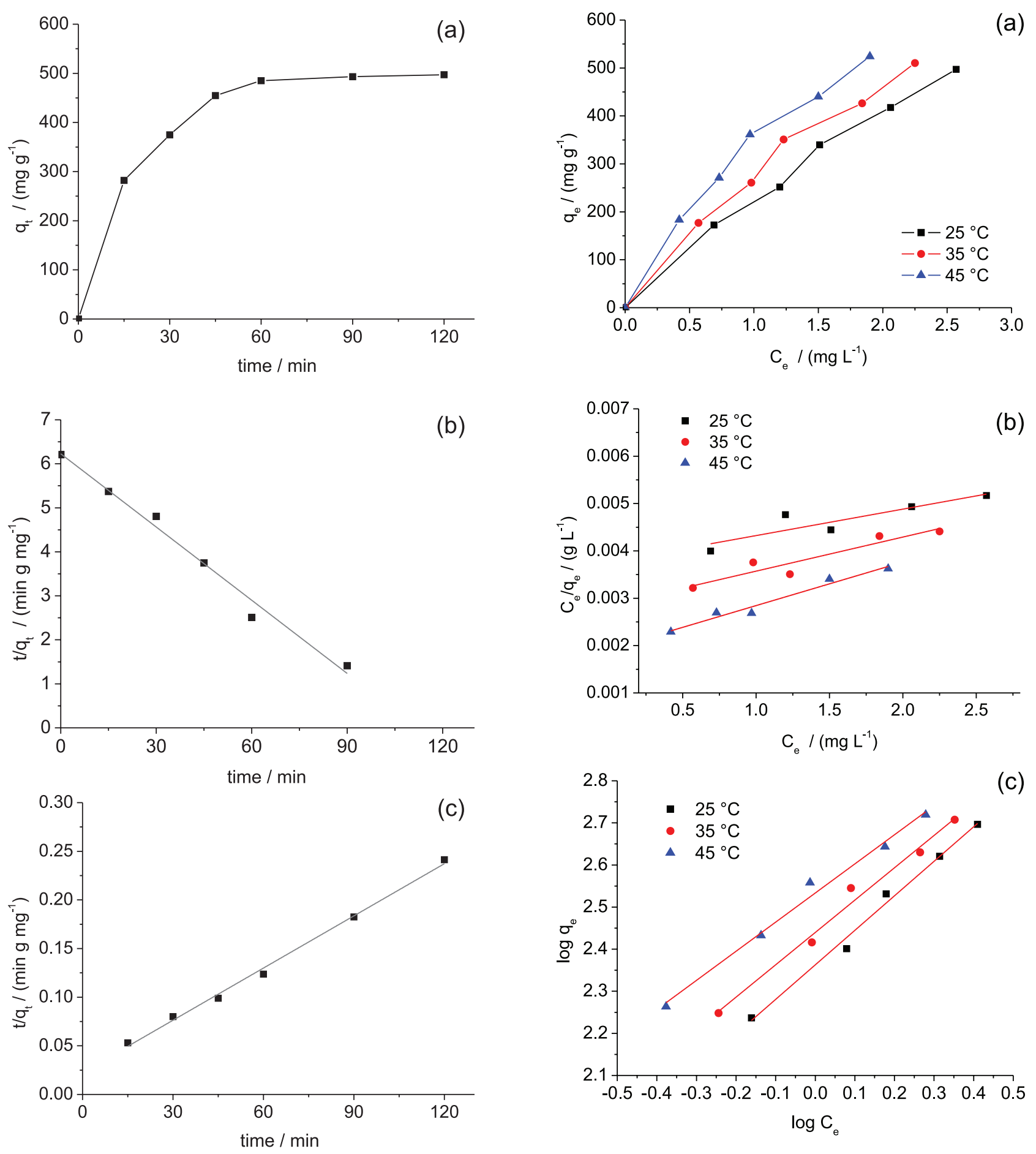

Figure 8. (a) Adsorption kinetics in aqueous solution of AR; (b) pseudofirst-order adsorption rates; (c) pseudo-second-order adsorption rates.

\section{Conclusions}

The TMGO was prepared and characterized in this study. The adsorption of AR for TMGO followed pseudosecond-order kinetics and the equilibrium data fitted well with the Freundlich isotherm model. TMGO showed satisfied reusability in five cycle adsorptions as well.

Figure 9. (a) Adsorption isotherms of AR with TMGO; (b) fitting by Langmuir model; (c) fitting by Freundlich model.

According to the performance of TMGO, it could become a promising material in removing dyes from water.

\section{Acknowledgments}

This work was financially supported by Talent Introduction Project of Hubei Normal University in 2015. 
Table 1. Isotherm parameters for the adsorption of AR

\begin{tabular}{lcccc}
\hline \multirow{2}{*}{ Model } & \multirow{3}{*}{ Parameter } & \multicolumn{3}{c}{ Parameter value } \\
\cline { 3 - 5 } & & $25{ }^{\circ} \mathrm{C}$ & $35{ }^{\circ} \mathrm{C}$ & $45{ }^{\circ} \mathrm{C}$ \\
\hline \multirow{3}{*}{ Langmuir } & $\mathrm{q}_{\mathrm{m}}\left(\mathrm{mg} \mathrm{g}^{-1}\right)$ & 497.2 & 510.2 & 524.2 \\
& $\mathrm{~b}$ & 0.1486 & 0.2525 & 0.4759 \\
& $\mathrm{R}^{2}$ & 0.7436 & 0.8505 & 0.9560 \\
\hline \multirow{2}{*}{ Freundlich } & $1 / \mathrm{n}$ & 0.8199 & 0.7682 & 0.6917 \\
& $\mathrm{k} /\left(\mathrm{mg} \mathrm{g}^{-1}\right)$ & 230.5 & 275.2 & 341.5 \\
& $\mathrm{R}^{2}$ & 0.9878 & 0.9819 & 0.9852 \\
\hline
\end{tabular}

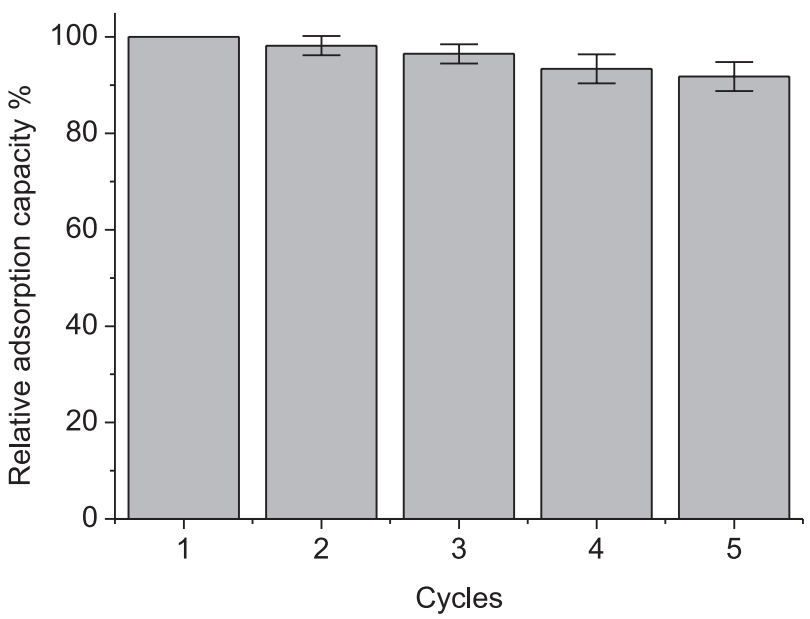

Figure 10. Reusability of TMGO.

\section{References}

1. Saber-Samandari, S.; Saber-Samandari, S.; Joneidi-Yekta, H.; Mohseni, M.; Chem. Eng. J. 2017, 308, 1133.

2. Nguyen-Le, M. T.; Lee, B. K.; Chem. Eng. J. 2015, 281, 20.

3. Hahm, H.; Kim, S.; Ha, H.; Jung, S.; Kim, Y.; Yoon, M.; Kim, M.; CrystEngComm 2015, 17, 8418.

4. Tripathi, B. P.; Dubey, N. C.; Stamm, M.; J. Hazard. Mater. 2013, 252-253, 401

5. Wang, J.; Zhou, Q.; Song, D.; Qi, B.; Zhang, Y.; Shao, Y.; Shao, Z.; J. Sol-Gel Sci. Technol. 2015, 76, 501.

6. Shen, J.; Li, Z.; Wu, Y. N.; Zhang, B.; Li, F.; Chem. Eng. J. 2015, 264, 48.

7. Son, B. H. D.; Mai, V. Q.; Du, D. X.; Phong, N. H.; Khieu, D. Q.; J. Chem. 2016, 11.

8. Ozbay, N.; Yargic, A. S.; Yarbay-Sahin, R. Z.; Onal, E.; J. Chem. 2013, 2013, article ID 234904.

9. Wang, Y.; Li, Z.; Wang, J.; Li, J.; Lin, Y.; Trends Biotechnol. 2011, 5, 205.

10. Dikin, D. A.; Sasha, S.; Zimney, E. J.; Piner, R. D.; Dommett, G. H. B.; Guennadi, E.; Nguyen, S. B. T.; Ruoff, R. S.; Nature 2007, $448,457$.
11. Dreyer, R. D.; Park, S.; Bielawski, C. W.; Ruoff, R. S.; Chem. Soc. Rev. 2010, 39, 228.

12. Ma, Y. X.; Li, Y. F.; Zhao, G. H.; Yang, L. Q.; Wang, J. Z.; Shan, X.; Yan, X.; Carbon 2012, 50, 2976.

13. Gao, J.; Gu, H.; Xu, B.; Acc. Chem. Res. 2009, 42, 1097.

14. Ahalya, K.; Suriyanarayanan, N.; Priyadharsini, N.; Nanosci. Nanotechnol. Lett. 2015, 7, 134.

15. Ning, F. J.; Qiu, T. T.; Wang, Q.; Peng, H. L.; Li, Y. B.; Wu, X. Q.; Zhang, Z.; Chen, L. X.; Xiong, H.; Food Chem. 2017, 221, 1797.

16. Sun, B. L.; Gou, Y. Q.; Ma, Y. L.; Zheng, X. P.; Bai, R. B.; Abdelmoaty, A. A. A.; Hu, F. D.; Biosens. Bioelectron. 2017, $88,55$.

17. Fan, J. P.; Liao, D. D.; Xie, Y. L.; Zheng, B.; Yu, J. X.; Cao, Y. H.; Zhang, X. H.; Peng, H. L.; J. Appl. Polym. Sci. 2017, 134,9 .

18. Liu, J.; Wang, H. J.; Li, X. C.; Jia, W. H.; Zhao, Y. P.; Ren, S. L.; Fuel 2017, 189, 79.

19. Marcano, D. C.; Kosynkin, D. V.; Berlin, J. M.; Sinitskii, A.; Sun, Z.; Slesarev, A.; Alemany, L. B.; Lu, W.; Tour, J. M.; ACS Nano 2010, 4, 4806.

20. Sivashankar, R.; Sathya, A. B.; Krishnakumar, U.; Sivasubramanian, V.; Ecotoxicol. Environ. Saf. 2015, 121, 149.

21. Jiao, F.; Yu, J.; Song, H.; Jiang, X.; Yang, H.; Shi, S.; Chen, X.; Yang, W.; Appl. Clay Sci. 2014, 101, 30.

22. Chakraborty, P.; Nagarajan, R.; Appl. Clay Sci. 2015, 118, 308.

23. Bhadra, M.; Roy, S.; Mitra, S.; Desalination 2016, 378, 37.

24. Liu, S.; Yu, B.; Zhang, T.; J. Mater. Chem. A 2013, 1, 13314.

25. Xu, Y.; Bai, H.; Lu, G.; Li, C.; Shi, G.; J. Am. Chem. Soc. 2008, $130,5856$.

26. Jin, Y.; Huang, S.; Zhang, M.; Jia, M.; Synth. Met. 2013, 168, 58.

27. Ning, F.; Qiu, T.; Wang, Q.; Peng, H.; Li, Y.; Wu, X.; Zhang, Z.; Chen, L.; Xiong, H.; Food Chem. 2017, 221, 1797.

28. Pakapongpan, S.; Poo-arporn, R. P.; Mater. Sci. Eng. C 2017, 76, 398.

29. Sahraei, R.; Sekhavat Pour, Z.; Ghaemy, M.; J. Cleaner Prod. 2017, 142, 2973.

30. Ma, Y. X.; Xing, D.; Shao, W. J.; Du, X. Y.; La, P. Q.; J. Colloid Interface Sci. 2017, 505, 352.

31. Lu, Z.; Yu, J.; Zeng, H.; Liu, Q.; Sep. Purif. Technol. 2017, 183, 249.

32. Yang, Y.; Hu, X.; Zhao, Y.; Cui, L.; Huang, Z.; Long, J.; Xu, J.; Deng, J.; Wu, C.; Liao, W.; J. Colloid Interface Sci. 2017, 495, 68 .

33. Eslaminejad, T.; Nematollahi-Mahani, S. N.; Ansari, M.; J. Magn. Magn. Mater. 2016, 402, 34.

34. Zhang, Y. R.; Su, P.; Huang, J.; Wang, Q. R.; Zhao, B. X.; Chem. Eng. J. 2015, 262, 313.

35. Song, W.; Gao, B.; Xu, X.; Xing, L.; Han, S.; Duan, P.; Song, W.; Jia, R.; Bioresour. Technol. 2016, 210, 123. 
36. Wang, S.; Zhai, Y. Y.; Gao, Q.; Luo, W. J.; Xia, H.; Zhou, C. G.; J. Chem. Eng. Data 2014, 59, 39.

37. Saratale, R. G.; Sivapathan, S. S.; Jung, W.; Kim, H. Y.; Saratale, G. D.; Kim, D. S.; J. Environ. Sci. Health, Part A 2016, 51, 164.

38. Yu, S.; Zhai, L.; Wang, Y.; Liu, X.; Xu, L.; Cheng, L.; J. Environ. Chem. Eng. 2015, 3, 752.
39. Jiang, T.; Liang, Y. D.; He, Y. J.; Wang, Q.; J. Environ. Chem. Eng. 2015, 3, 1740.

Submitted: June 14, 2017

Published online: August 2, 2017 